\title{
Significance of analysing chemical composition of renal stones
}

\section{Koirala $\mathrm{S}^{1}$}

${ }^{I}$ Department of Pathology, Kathmandu Pathology Laboratory, Kathmandu, Nepal

\section{Keywords: \\ Renal stone; Calcium; Ammonium; Diet.}

\begin{abstract}
Background: This article aims to decipher chemical composition of renal stones and briefly outline laboratory tests and dietary habitual changes aimed at preventing stone recurrence. It is based on analysis of 95 renal stones received in a private lab in Kathmandu over a period of 1 year.

Materials and Methods: Renal stones were analysed using simple qualitative biochemical tests. The stones were checked for presence of calcium, magnesium, ammonium, oxalate, phosphate, uric acid, cystine and carbonate.

Results: Calcium was present in $97.8 \%$, ammonium was present in $98.9 \%$, phosphate was present in $25.2 \%$, uric acid was present in $17.8 \%$, magnesium was present in $10.5 \%$, carbonate was present in $2.1 \%$ and cystine was not present in any of the stones. Most of the stones were composed of mixture of two or more than two of the above mentioned elements.

Conclusion: Most stones are mixture of more than two cations and anions. Studies on larger test samples and if possible in correlation with routine examination of urine and urinary electrolyte excretion in a 24 $\mathrm{hr}$ urine sample would further aid in efforts aimed at preventing stone recurrence.
\end{abstract}

\section{INTRODUCTION}

Urolithiasis is a common and a major cause of morbidity worldwide. However, establishing the presence of a kidney stone should not herald an endpoint for any diagnostic and therapeutic efforts. ${ }^{1}$ The chemical characterization of urinary calculi was initiated by J. F. Heller in the nineteenth century. ${ }^{2}$ Majority of renal stones

\section{Correspondence:}

Dr. Sudhamsu Koirala, MD

Consultant Pathologist

Kathmandu Pathology Laboratory, Kathmandu, Nepal

Email:sudhamsu.koirala@gmail.com are idiopathic, probably involved in stone formation are the confluence of predisposing factors. ${ }^{3}$ Current studies in Western world are aimed at finding the etiology and preventing stone recurrence following an episode of renal stone. However, multitude of tests aimed at finding the etiology is not feasible in context of developing countries where the main aim should be prevention of recurrence. Efforts aimed at prevention of recurrence starts with analysis of stone after first episode. These efforts will yield better results if carried out in conjunction with analysis of urinary electrolytes in 24-hr urine sample. ${ }^{4}$ The results of stone analysis in conjunction of 24-hr urinary electrolyte 
can form a basis of dietary advice aimed at preventing recurrence. With advancement of medical technology, the stones are nowadays analysed not only for their chemical composition but also for their physical structure using techniques such as stereoscopic microscopy,infrared spectroscopy and scanning electron microscopy coupled with X-ray dispersive energy microanalysis. ${ }^{5}$

\section{MATERIALS AND METHODS}

This study was carried out in private laboratory based in Kathmandu. All the renal stones sent to Kathmandu Pathology laboratory from different hospitals and clinic of the city during the period of May 2012 to April 2013 were analysed using qualitative biochemical technique with the aid of kit manufactured by BIOLABO SA. The stones were pulverized. 50mg of stone powder was mixed with 10 drops of $1.65 \mathrm{M} \mathrm{Hcl}$ to form a reagent used to test for ammonium, cystine, phosphate, magnesium, uric acid and oxalate. $50 \mu 1$ of this reagent was mixed with $5 \mathrm{ml}$ of distilled water to form another reagent used to test presence of Calcium. Distilled water was used as a negative control to establish the authenticity of results.

\section{RESULTS}

A total of 95 stones were analyzed. Most of them were received in pieces. Table1 shows composition of all stones. Most of the stones were composed of mixture of two or more than two of tested chemicals. The most common stone contained the mixture of calcium ammonium oxalate $(57.75 \%)$. The mixture of calcium and magnesium as cations akin to struvite stones were present in 9 cases $(9.5 \%$ ) (Table $2)$. seventeen stones $(17.9 \%)$ contained uric acid in mixture with other chemicals (Table 3). Fig 3. shows percentage of each chemical in terms of total number of cases.
Calcium was present in $97.8 \%$, ammonium was present in $98.9 \%$, phosphate was present in $25.2 \%$, Uric acid was present in $17.8 \%$, magnesium was present in $10.5 \%$, carbonate was present in $2.1 \%$ and cystine was not found in any of the stones (fig. 1).

There were 52 female patients and 43 male patients. Female to male ratio was 1.2:1. Ages of the patient ranged from 18 to 67 years with mean age of 36 yrs. Maximum stones formers 58 were between the ages of 21-40 (fig. 2).

Carbonate was detected in 2 stones. Carbonate signifies presence of organic nidus upon which inorganic ions are deposited to form stones. Cystine was not detected in any of the stones analyzed.

\section{DISCUSSION}

The practical purpose of analyzing chemical composition of stones done in various countries around the globe is to prevent recurrence after a single episode. The severe colicky pain associated with an episode and subsequent surgical procedures for removal are causes of concern to a patient who has been diagnosed with renal calculi. Three prospective studies have shown that if patient presenting with first stone are not counseled on risks of recurrence, $4-50 \%$ will reccur. $^{6}$

No age or sex can be considered safe from urolithiasis. ${ }^{7}$ in this study, cases of female were more than of male in the ratio 1.2:1. This differs with the usual trend seen in various studies where male outnumber female by a ratio of $2-3: 1 .^{8} \mathrm{In}$ this study, stones were most common in the third and fourth decade of life. fifty-eight stone formers were between ages 21-40. Various studies show that most patients are between 30-40 years, when they first present with stones. ${ }^{9}$

Table 1: Mixtures of Cations and anions in stone detected

\begin{tabular}{lcc}
\hline \multicolumn{1}{c}{ Mixture of chemicals in stones } & No.of stones & $\%$ of total \\
\hline Calcium ammonium oxalate & 55 & $57.75 \%$ \\
\hline Calcium oxalate and calcium phosphate + Ammonium & 12 & $12.8 \%$ \\
\hline Ammonium oxalate and ammonium phosphate & 1 & $1.05 \%$ \\
\hline Calcium magnesium phosphate & 1 & $1.05 \%$ \\
\hline Calcium ammonium and uric acid phosphate & 2 & $2.1 \%$ \\
\hline Calcium ammonium magnesium phosphate & 3 & $3.05 \%$ \\
\hline Calcium ammonium magnesium phosphate and uric acid & 1 & $1.05 \%$ \\
\hline Calcium ammonium oxalate and uric acid & 13 & $13.8 \%$ \\
\hline Calcium magnesium ammonium oxalate & 1 & $1.05 \%$ \\
\hline Calcium ammonium magnesium phosphate and carbonate & 2 & $2.1 \%$ \\
\hline Calcium ammonium magnesium oxalate and phosphate & 1 & $1.05 \%$ \\
\hline Calcium ammonium oxalate phosphate and uric acid & 1 & $1.05 \%$ \\
\hline Ammonium oxalate & 1 & $1.05 \%$ \\
\hline Calcium and ammonium & 1 & $1.05 \%$ \\
\hline Total & 95 & $100 \%$ \\
\hline
\end{tabular}


Table 2: Stones containing calcium and magnesium as cations (akin to struvite stones)

\begin{tabular}{ll}
\hline \multicolumn{1}{c}{ Calcium magnesium phosphate } & 1 \\
\hline Calcium ammonium magnesium phosphate & 3 \\
\hline Calcium ammonium magnesium phosphate and uric acid & 1 \\
\hline Calcium magnesium ammonium oxalate & 1 \\
\hline Calcium ammonium magnesium phosphate and carbonate & 2 \\
\hline Calcium ammonium magnesium oxalate and phosphate & 1 \\
Total and Percentage of total stones that contained calcium and Magnesium as cation & $9(9.5 \%)$
\end{tabular}

Table 3: Stones containing uric acid as anion

Calcium ammonium oxalate and uric acid

Calcium ammonium and uric acid phosphate

Calcium ammonium oxalate phosphate and uric acid

Calcium ammonium magnesium phosphate and uric acid

Total and Percentage of total stones that contained uric acid as anion

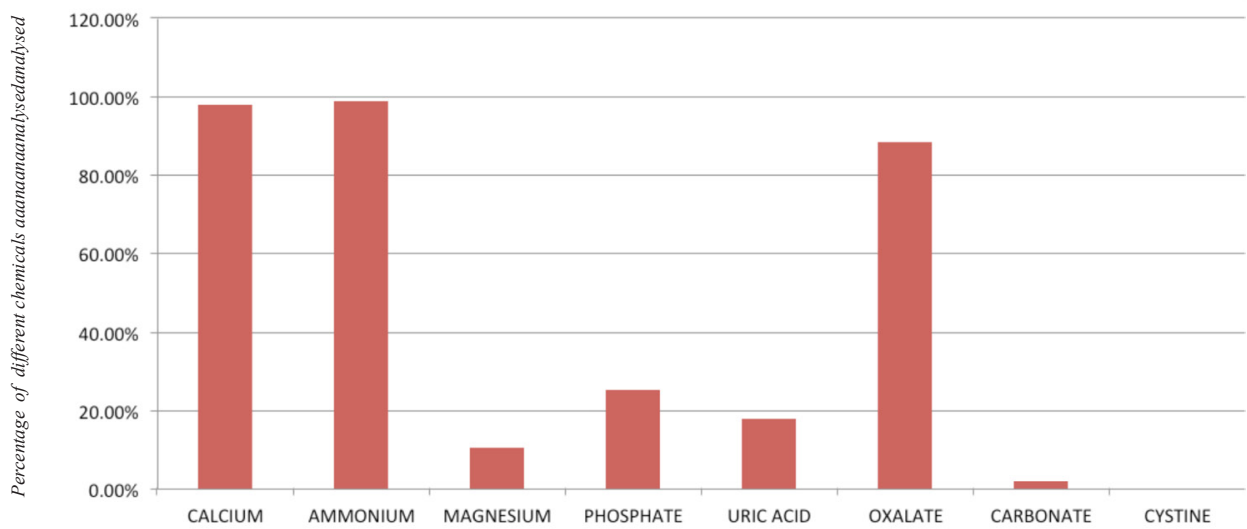

Figure 1: Percentage of different elements in the renal stones examined.

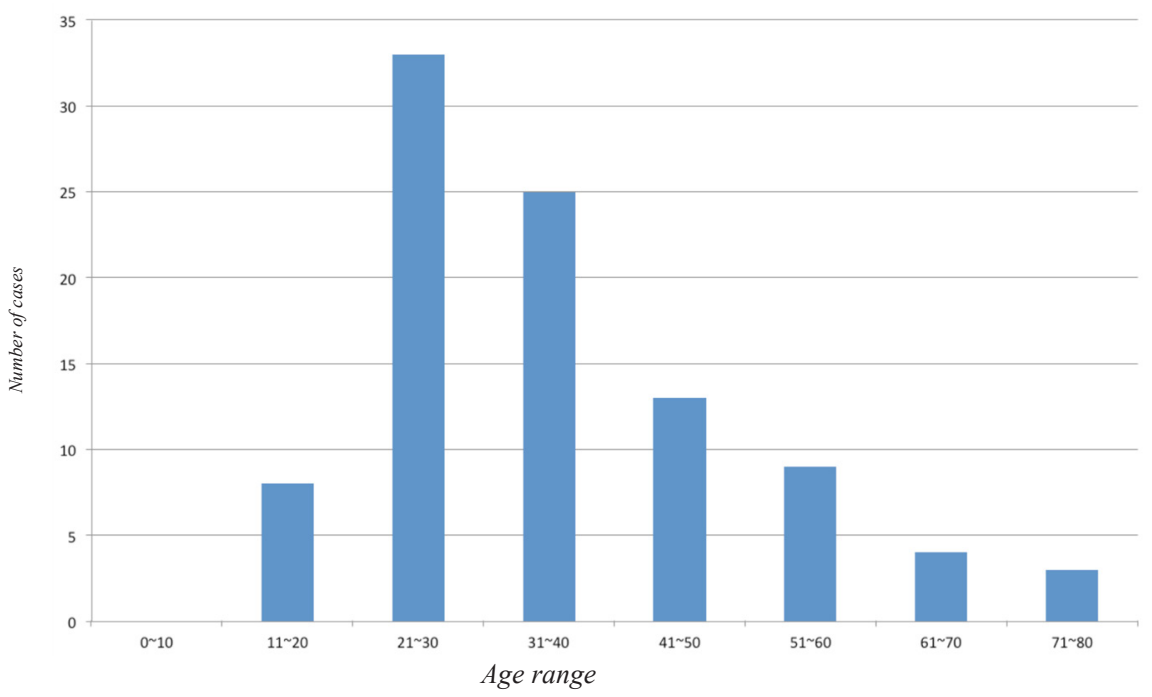

Figure 2: Age wise distribution of cases of urolithiasis 
Regarding the composition of stones, most stones were mixture of multiple cations and anions. This is similar to a study done by Choo-Kang et al. ${ }^{10}$ In qualitative and indeed even in quantitative methods, it is near impossible to classify the stones as calcium oxalate, calcium phosphate, mixture of calcium oxalate with calcium phosphate, struvite or pure uric acid and cystine stones as all of the cations and anions tested will be present in trace amounts. ${ }^{11}$ Our results were unique that Ammonium was present in almost all the stones $(98.9 \%)$. A thorough literature search failed to answer this ubiquity of ammonium however as mentioned before the significance of this finding can be substantiated only by determining quantity of ammonium in these stones. Most of these stones probably contain calcium as the major cation and phosphate or oxalate as the major anion as is the norm in various studies. ${ }^{12-15}$ Another point in favour of this logic is that Calcium stones are predominant in acidic urine while ammonium containing stones are more common in alkaline urine.

Most stone formers following health tips provided in social media decrease intake of Calcium in their diet after the first episode. ${ }^{16,17}$ This habit is justified by predominance of calcium containing stones in most studies. However the contribution of phosphate, oxalate, magnesium and uric acid in stone formation cannot be overlooked, furthermore dropping calcium from the diet altogether may be detrimental to heath given the dependence of various systems of body on calcium; especially the musculoskeletal system. ${ }^{18}$

Counseling on improving dietary habits to prevent recurrence depends not only on composition of stones but also on analysis of urinary electrolytes in 24-hr urine sample. Analysis of 24-hr urine sample for urinary electrolytes is beyond this article but It is well known that the raised excretion of oxalate, uric acid, calcium and phosphorus in the urine increase the formation of stones, while raised excretion of citrate, magnesium, albumin and alkali in urine decrease chances ofstone formation. ${ }^{4}$ In a nut shell, increase in amount of water, potassium containing fruits and decrease in animal proteins and sodium confer protection from calcium stones and uric acid stones. ${ }^{4}$ Struvite stone more often than not have alkaline urine usually in presence of bacteria, such cases can be dealt with control of infection. ${ }^{19}$ The driving force behindstruvite stones is infection of the urine with urease-producing bacteria. It has beenproposed that the urease hydrolyses urea,resulting in ammoniacal urine, alkalinity andstone formation. ${ }^{20}$

Various techniques have evolved that not only determine the chemical composition of the stones but also their physical structure. These include stereoscopic microscopy,infrared spectroscopy and scanning electron microscopycoupled, with X-ray' dispersive energy microanalysis. ${ }^{5}$

However, these techniques require financial strength and trained manpower beyond the capacity prevalent in developing countries.

\section{CONCLUSION}

This study is based on simple qualitative biochemical study .This technique is simple and feasible for developing countries in terms of financial strength and available manpower. Proper dietary management following test results can substantially reduce recurrence of stones. Similar studies on larger test samples possibly in correlation with routine examination of urine and urinary electrolyte excretion in a $24 \mathrm{hr}$ urinary sample would further aid in efforts aimed at preventing stone recurrence.

\section{REFERENCES}

1. Moe OW. Kidney stones: pathophysiology and medical management. Lancet 2006;367:333-44. CrossRef

2. Richet G. The chemistry of urinary stones around 1800: a first in clinical chemistry. Kidney Int.1995;48:876-86. CrossRef

3. Charles E, Fogo AB. The kidney and its collecting system, In: Kumar V, Abbas AK, Fausto N, Mitchell RN eds. Basic pathology. 8ed.Elsevier: United states; 2007. pp571.

4. Jawalekar S, Surve VT, Bhutey AK. Twenty four hours urine and serum biochemical parameters in patients with urolithiasias. Nepal Med Coll J 2010;12: 5-7.

5. Grases F, García-Ferragut L, Costa-Bauz A. Analytical study of renal calculi : a new insight Recent Res DeveI in Pure \&Applied Anal Chem 1998; 1:187-206.

6. Joost J, Put ZA. Calcium oxalate stone former-five years stone recurrences. Br J Urol 1984;56:122-4.

7. Costa-Bauzá A, Ramis M, Montesinos V et al. Type of renal calculi: variation with age and sex. World J Urol 2007;25:415-21. CrossRef

8. Seitz C, Fajkovic H. Epidemiological gender-specific aspects in urolithiasis. World J Urol 2013;31:1087-92. CrossRef

9. Gault MH, Chafe L. Relationship of frequency, age, sex, stone weight and composition in 15,624 stones: comparison of results for 1980 to 1983 and 1995 to 1998 . J Urol 2000;164302-7.

10. Choo-Kang E. Chemical Composition of Urinary Tract Stones at the University Hospital of the West Indies. West Indian Med J 2008;57:427-30.

11. Jawalekar S, Surve VT, Bhutey AK. The composition and quantitative analysis of urinary calculi in patients with renal calculi. Nepal Med Coll J 2010;12:145-148.

12. Singh PP, Singh LB, Prasad SN, Singh MG. Urolithiasis in Manipur ( North Eastern region of India ): incidence and chemical composition of stones. Am J Clin Nutr 1978;31:1519-25.

13. Risal S,Risal P,Pandeya DP, Adhikari D,Bhattachraya CS, Singh PP, Shrestha ML. Spectrum of stones composition: A chemical analysis of renal stones of patients visiting NMCTH. Nepal Med Coll J. 2006;8:263-5

14. Pandeya A,Prajapati R,Panta P, Regmi A.Assessment of kidney stone and prevalence of its chemical compositions. Nepal Med Coll J. 2010;12:190-2.

15. Hashmi ZA, Ghazala B, Nawaz HA. Composition of renal stones: calcium oxalate stones are the most common in Northwest Pakistan. Journal of post graduate medical institute 2004;15:199-201.

16. How can kidney stones be prevented?Baltimore:The James Buchanan Brady UrologicalInstitute;19February2014.Availablefrom:http:// urology.jhu.edu/kidney/stonesprevention.php. 
17. 5 steps for preventing kidney stones. Harvard University: Harvard health publications Harvard Medical school;19 February2014. Available from http://www.health.harvard.edu/blog/5-steps-forpreventing-kidney-stones-201310046721

18. Pravina P, Sayaji D, Avinash M. Calcium and its Role in Human Body. International Journal of Research in Pharmaceutical and Biomedical Sciences 2013;4:659-68.
19. Abbona F, Boistelle R.Growth morphology and crystal habit of struvite crystals (MgNH4PO4.6H2O). J Cryst Growth1979;46:339-54. CrossRef

20. Mukhia R, Shrestha K, Dahal P, Sharma VK. Study on chemical composition of urinary stones association with urinary tract infection. Post graduate Med Journal2001;8:1-5. 